\title{
Supplementary Methods and Supporting Material
}

for "Capturing Intermediate Structures of Alzheimer's $\beta$-Amyloid, $A \beta(1-40)$, by Solid-State NMR Spectroscopy" by Sandra Chimon and Yoshitaka Ishii

\section{Complete list of Ref. 7 and Ref. 12:}

(7) Chromy, B. A.; Nowak, R. J.; Lambert, M. P.; Viola, K. L.; Chang, L.; Velasco, P. T.; Jones, B. W.; Fernandez, S. J.; Lacor, P. N.; Horowitz, P.; Finch, C. E.; Krafft, G. A.; Klein, W. L. Biochemistry 2003, 42, 12749-12760.

(12) Hou, L. M.; Shao, H. Y.; Zhang, Y. B.; Li, H.; Menon, N. K.; Neuhaus, E. B.; Brewer, J. M.; Byeon, I. J. L.; Ray, D. G.; Vitek, M. P.; Iwashita, T.; Makula, R. A.; Przybyla, A. B.; Zagorski, M. G. J. Am. Chem. Soc. 2004, 126, 1992-2005.

\section{Material and Methods}

\section{$\underline{\text { Reagents }}$}

Fmoc-protected amino acids and Wang resins were purchased from Peptide International (Louisville,

$\mathrm{KY}$ ). Uniformly ${ }^{13} \mathrm{C}$ - and ${ }^{15} \mathrm{~N}$-labeled amino acids were purchased from Sigma-Aldrich/Isotec (St. Louis, MO). Other reagents for peptide synthesis were purchased from Applied Biosystems (ABI, Foster City, CA). $\mathrm{NaCl}, \mathrm{NaN}_{3}, \mathrm{KH}_{2} \mathrm{PO}_{4}$, and $\mathrm{Na}_{2} \mathrm{HPO}_{4}$ were purchased from Fisher Scientific (Hampton, $\mathrm{NH}$ ). Purified water (double deionized and distilled) was prepared using a High-Q 103 S water still system (High-Q Corp., Wilmette, IL). The purified water was used for all the peptide incubations in the experiments. All other reagents were obtained from Sigma-Aldrich.

\section{Synthesis of $A \beta(1-40)$}

The 40-residue human Alzheimer's $\beta$ peptide, $A \beta(1-40)$, is the most abundant $A \beta$ species. ${ }^{1}$ Although 42-residue $A \beta(1-42)$, a primary component of Alzheimer's plaques, aggregates more readily than $\mathrm{A} \beta(1-40)^{2}$ and may form distinctive small oligomers, ${ }^{3}$ both $\mathrm{A} \beta$ species are known to form similar toxic intermediates $^{4}$ and fibrils. ${ }^{5,6}$ Also, detailed structural basis has been obtained for fibrillized A $\beta(1-40) .{ }^{6,7}$ For these reasons, we selected $A \beta(1-40)$ as a suitable system for structural studies of the intermediate species in misfolding of $A \beta$ peptides. 
A $\beta(1-40)\left(\mathrm{NH}_{2}\right.$-DAEFRHDSGY EVHHQKLVFF AEDVGSNKGA IIGLMVGGVV-COOH) was synthesized and purified as described previously using solid-phase synthesis with standard FMOC synthesis and cleavage protocols and HPLC purification. ${ }^{7}$ The synthesis was performed with a Symphony peptide synthesizer (Protein Technologies Inc., Tucson, AZ) in the UIC Research Resource Center (RRC) or with an ABI 433 peptide synthesizer in the UIC Department of Chemistry. No batch-to-batch dependence of A $\beta(1$ 40) was observed in incubation-time dependence of fluorescence with a thioflavin $\mathrm{T}$ (ThT) dye or in transmission electron microscope (TEM) images. The synthesized peptides were purified by reverse-phase HPLC with a C18 column (Grace Vydac, Hesperia, CA) using an acetonitrile/water concentration gradient ranging from $26 / 74$ to $90 / 10$ with $0.1 \%$ trifluoroacetic acid. The A $\beta$ peptide was eluted approximately at the acetonitrile/water ratio of 37/63. The collected sample was immediately frozen and lyophilized. Purity of the $\mathrm{A} \beta$ samples was determined based on the MALDI-TOF mass spectra collected at UIC RRC to be approximately $90 \%$ and $95 \%$ before and after the HPLC purification, respectively. The purified peptide sample was stored at $-20{ }^{\circ} \mathrm{C}$ until it was used.

For ${ }^{13} \mathrm{C}$ solid-state NMR (SSNMR) data (Fig. 2), ${ }^{13} \mathrm{C}$ - and ${ }^{15} \mathrm{~N}$-labeled $\mathrm{A} \beta(1-40)$ was synthesized.

${ }^{15} \mathrm{~N}$-labeling was introduced for future experiments. Fmoc protection of uniformly ${ }^{13} \mathrm{C}$ - and ${ }^{15} \mathrm{~N}$-labeled amino acids was performed at the UIC RRC using the protocol of Fields et al. ${ }^{8}$ Standard solid-phase peptide synthesis was performed with the labeled Fmoc-protected amino acids to introduce labeling at the selected residues (Va118, Phe19, Ala21, Gly33, Leu34). The labeled sample was used without any dilution with an unlabeled A $\beta$ sample for SSNMR measurements.

\section{Aß Peptide solution and physical separation by centrifugation}

A solution of $2.0 \mathrm{mM} \mathrm{A} \beta$ (1-40) was prepared by first dissolving $\mathrm{A} \beta$ (1-40) peptides in purified water cooled in an ice bath. The peptide mixture was then briefly vortexed and checked with a fluorescence spectrometer to verify that there is the minimum level of pre-formed fibrils $(<0.010$ at $A \beta$ concentration of $25 \mu \mathrm{M}$ ) (see Fluorescence section below for more detailed information). The $A \beta(1-40)$ solution was diluted to the final $\mathrm{A} \beta$ concentration of $100 \mu \mathrm{M}$ with a standard buffer solution at $4{ }^{\circ} \mathrm{C}$ and $\mathrm{pH} 7.4(10 \mathrm{mM}$ 
phosphate, $0.02 \% \mathrm{NaN}_{3}, 5 \mathrm{mM} \mathrm{NaCl}$ ), which had been filtered with a $0.22 \mathrm{um}$ Millex-GC unit (Millipore, Bedford MA) before the dilution. The $\mathrm{A} \beta$ solution was sonicated for 3 minutes in an ice bath and then filtered with a 50-kDa molecular-weight-cut-off (MWCO) filter, Centricon YM-50 (Millipore, Bedford MA) at $4{ }^{\circ} \mathrm{C}$ and 3,200 g for 12 minutes to remove any preformed aggregates. The $\mathrm{pH}$ was confirmed to be 7.4 or a minor adjustment was made if necessary. The peptide solution of typically $20-40 \mathrm{~mL}$ was then incubated at various incubation temperatures in a 50-mL Falcon conical tube (BD Biosciences, Rockville, MD). The incubated sample was not constantly agitated, but gently mixed every 1-4 hours for sampling aliquots for fluorescence measurements throughout incubation times.

To collect the "soluble" components of $A \beta(1-40)$ from the incubated $A \beta(1-40)$ solution, a quick centrifugation was performed for $1-\mathrm{mL}$ solutions in $1.5-\mathrm{mL}$ microvials with an Eppendorf 5414D microcentrifuge (Eppendorf, Westbury, NY) for 15 minutes at 13,200g. In studies of incubation-time dependence of fluorescence, a solution of $25 \mu \mathrm{L}$ was collected from the top of the solution after the centrifugation. We confirmed by EM that this procedure generally removes fibrils and protofibrils, which are a truncated form of fibrils, effectively.

In ${ }^{13} \mathrm{C}$ SSNMR analysis of the intermediates or monomeric forms, the top $70 \%$ portion of the solutions sampled at $t=0$ and $52 \mathrm{~h}$ were collected, respectively. The fluorescence level for the aliquot from the top $70 \%$ portion was nearly identical to that for the aliquot collected from the top of the solution at $0 \leq t$ $\leq 52 \mathrm{~h}$ (i.e. before fibril formation). For each of the 0-hour and 52-hour samples, $8.8 \mathrm{mg}$ of $\mathrm{A} \beta(1-40)$ was incubated in a buffer of $20.0 \mathrm{~mL}$. It was confirmed that no fibrils or protofibrils were observed in EM images for the top $70 \%$ portion after this centrifugation procedure at $t \leq 52 \mathrm{~h}$ in the incubation at $4{ }^{\circ} \mathrm{C}$. The collected samples were immediately frozen in liquid nitrogen and lyophilized for SSNMR analysis. The lyophilized samples used for Fig 2(a, b) were 7.0-7.1 mg including salts $\left(\mathrm{NaN}_{3}\right.$, phosphate buffer, $\left.\mathrm{NaCl}\right)$; the sample contains approximately $4.5 \mathrm{mg}$ of the $\mathrm{A} \beta$ peptides. The salt amount in the samples was estimated by weighing the salts obtained by lyophilizing the top $70 \%$ and bottom $30 \%$ fractions of a centrifuged buffer without the peptides; it was noticed that the salt concentration was considerably higher at the bottom. The 
low molecular-weight species used for SSNMR in Fig. 2(d) was obtained by filtering the A $\beta(1-40)$ solution sampled at $t=52 \mathrm{~h}$ with a 50-kDa -MWCO filter, Microcon YM50 (Millipore) for 12 mins at 12,000 $\mathrm{g}$ and lyophilizing the filtrate as described above. The fibril sample used for ${ }^{13} \mathrm{C}$ SSNMR in Fig. 2(c) was prepared by incubating the labeled $\mathrm{A} \beta(1-40)$ of $8.8 \mathrm{mg}$ at $25^{\circ} \mathrm{C}$ for 4 days to obtain matured fibrils. The $\mathrm{A} \beta$ solution was centrifuged for 15 mins at 13,200 g, and the precipitate at the bottom of the sample tube was collected. The fibril sample including the salts was $4.4 \mathrm{mg}$, about $2.2 \mathrm{mg}$ of which was estimated to be the peptides. We also prepared the labeled fibril sample incubated at $4{ }^{\circ} \mathrm{C}$ for 3 days. The peak positions in an $1 \mathrm{D}{ }^{13} \mathrm{C}$ CPMAS spectrum for this sample were nearly identical with those for the sample prepared at $25^{\circ} \mathrm{C}$, within $0.2 \mathrm{ppm}$ difference except for ${ }^{13} \mathrm{C}_{\alpha}$ for Val18 $(0.5 \mathrm{ppm})$, although the line widths appear to be slightly broader.

\section{Thioflavin-T (ThT) fluorescence assay:}

Fluorescence measurements were performed on a Hitachi F-2000 fluorescence spectrometer (Hitachi, Tokyo, Japan) at an excitation of $446 \mathrm{~nm}$ and emission of $482 \mathrm{~nm}$, as previously described. ${ }^{9}$ ThT was used to detect aggregated $A \beta$ involving $\beta$-strands. It has been known that upon binding on $\beta$-sheet regions of amyloid aggregates, ThT shifts its maximum excitation and emission wavelengths $\left(\lambda_{\mathrm{ex}}, \lambda_{\mathrm{em}}\right)$ from $(340 \mathrm{~nm}, 430 \mathrm{~nm})$ to $(440 \mathrm{~nm}, 480 \mathrm{~nm}) .{ }^{10}$ This permits quantitative identification of $\beta$-sheet rich amyloid aggregates including non-fibril aggregates. ${ }^{11}$ A $3 \mu \mathrm{M}$ thioflavin $\mathrm{T}$ (ThT) solution, $\mathrm{pH}$ 8.6, was prepared by dissolving solid ThT (Sigma-Aldrich ) in a $50 \mathrm{mM}$ glycine- $\mathrm{NaOH}$ buffer, ${ }^{12}$ and stored at $25^{\circ} \mathrm{C}$ in a brown bottle to prevent quenching by light until usage. The $100 \mu \mathrm{M} A \beta(1-40)$ peptide solution of $25 \mu \mathrm{L}$ was added to $2 \mathrm{~mL}$ of the ThT solution so that the peptide is diluted to $1.25 \mu \mathrm{M}$. The fluorescence of the solution was measured in a 10-mm Suprasil Quartz cell (Fisher Scientific, 14-385-918B) immediately after mixture under dark conditions to prevent quenching of fluorescence. To collect the incubation time dependence data in Fig. $1(a, b)$, the fluorescence was measured for (a) four and (b) ten separate incubations. In each incubation trial, the fluorescence level at 15-25 different incubation times was measured. In Fig. 1(a, b), the fluorescence was 
displayed as the average of more than (a) two or (b) three measurements for separate incubations. The measurements were less frequently performed after fibril formation [(a) $t>35 \mathrm{~h}$ and (b) $t>60 \mathrm{~h}$ ] because the fluorescence level became constant. It was found that the experiments were highly reproducible and there were no significant outliers. The average of the standard deviations in the fluorescence measurements was (a) 0.003 and (b) 0.002 .

\section{Transmission electron microscopy:}

A JEOL JEM-1220 transmission electron microscope (TEM) at an accelerating voltage of $120 \mathrm{kV}$ was used for analysis of morphologies of aggregated $A \beta(1-40)$ peptides sampled at different incubation times. Unless otherwise mentioned, the incubated $A \beta(1-40)$ solution was gently mixed before the sampling. The sampled $A \beta(1-40)$ solution of $10 \mu$ was placed onto a carbon-coated Formvar 200-mesh copper grid (Electron Microscopy Sciences, Hatfield, PA) for 30 seconds. Excess solution was wicked dry with a tissue paper, and then negatively stained with $\sim 10$ ul of $2 \%$ uranyl acetate solution for 1 minute. After excess solution was again wicked dry and the grid was allowed to air dry, the peptide samples were analyzed. ${ }^{13}$

\section{Solid-state NMR experiment:}

All the experiments were performed with a Varian Infinity-plus SSNMR spectrometer with a 3.2mm Varian T3 triple-resonance MAS probe at $9.4 \mathrm{~T}\left({ }^{1} \mathrm{H}\right.$ frequency of $\left.400.2 \mathrm{MHz}\right)$. The spinning speed was set to $20,000 \pm 3 \mathrm{~Hz}$ throughout the experiments. In 1D CPMAS experiments in Fig. $2(\mathrm{a}-\mathrm{d})$, the ${ }^{13} \mathrm{C}$ RF field amplitude was linearly swept from $60 \mathrm{kHz}$ to $75 \mathrm{kHz}$ during a contact time of $1.0 \mathrm{~ms}$ while the ${ }^{1} \mathrm{H} \mathrm{RF}$ amplitude was kept constant at $88 \mathrm{kHz}$. For each spectrum, 512 scans of time-domain signals of $15 \mathrm{~ms}$ were accumulated with recycle delays of $3 \mathrm{~s}$ under ${ }^{1} \mathrm{H}$ ТPРM decoupling of $90 \mathrm{kHz},{ }^{14}$ and a Gaussian window function of $80 \mathrm{~Hz}$ was applied. For (a, b) approximately $4.5 \mathrm{mg}$ of labeled $\mathrm{A} \beta(1-40)$ was used while $2.2 \mathrm{mg}$ of fibrillized $\mathrm{A} \beta(1-40)$ was used for (c). In $2 \mathrm{D}{ }^{13} \mathrm{C} /{ }^{13} \mathrm{C}$ correlation SSNMR for Fig. 2(e), a fpRFDR ${ }^{13} \mathrm{C}-{ }^{13} \mathrm{C}$ dipolar recoupling sequence with a mixing time of $1.6 \mathrm{~ms}$ and a ${ }^{13} \mathrm{C} \pi$-pulse width of $13 \mu$ s was used. ${ }^{7,15} \quad{ }^{1} \mathrm{H}$ TPPM decoupling of $90 \mathrm{kHz}$ was employed during the $t_{1}$ and $t_{2}$ periods, while $\mathrm{cw}$ decoupling of the same 
amplitude was used during the mixing period. For each $t_{1}$ point, 146 scans of signals were accumulated with an acquisition period of $10 \mathrm{~ms}$ with recycle delays of $2.9 \mathrm{~s}$. A total of 180 complex $\mathrm{t}_{1}$ points were recorded with an increment of $34.5 \mu \mathrm{s}$. Gaussian window functions of $110 \mathrm{~Hz}$ and $90 \mathrm{~Hz}$ were applied along the $\mathrm{t}_{1}$ and $t_{2}$ time domains. An overall experimental time was 43 hours. Color coded solid-lines in the figure 2(e) connect cross peaks between directly bonded ${ }^{13} \mathrm{C}$ pairs to clarify the signal assignment (see Table S2 about the details of the assignment).

\section{Supporting Data}

\section{Additional solid-state NMR experiments for the sample used in Fig. 2(a)}

Because the signals in Fig. 2(a) were much weaker than those in Fig. 2(b), we examined whether the peptide actually existed in the sample. Although the relatively sharp lines with low intensities in (a) resemble those of $\beta$-sheet species in (b. c), the signals were attributed to a minor species because of the low signal intensities. The 0 -hour sample used for Fig. 2 (a) was resuspended in water and incubated at $4{ }^{\circ} \mathrm{C}$ for $96 \mathrm{~h}$. We confirmed that the ThT fluorescence indicated formation of fibrils (see the fluorescence assays below). ${ }^{13} \mathrm{C}$ CPMAS experiment for the lyophilized fibril sample $(3.5 \mathrm{mg})$ containing $\sim 1.8 \mathrm{mg}$ of the peptide reproduced the spectrum in Fig. 2(c). A newly prepared 0-hour sample also reproduced the spectrum in Fig. 2(a). These results clearly show that the signal intensities for a given sample substantially increase as $A \beta$ are converted into well-ordered $\beta$-sheet structures.

Initially, we considered the possibility that conformational disorder broadened out the missing signals in Fig. 2(a). However, there seems to be no indication of broader lines in the base of the ${ }^{13} \mathrm{C}$ CPMAS spectrum acquired with 2,560 scans for the 0-hour sample. Suspecting the existence of dynamics, we also performed ${ }^{13} \mathrm{C}$ MAS experiments for the 0 -hour sample by a single $\pi / 2$-pulse excitation with ${ }^{1} \mathrm{H}$ decoupling; this also did not produce strong signals. The missing signals may be, for example, explained by existence of slow dynamics in the unstructured $A \beta$ that interferes with ${ }^{1} \mathrm{H}$ decoupling or/and MAS. Although further 
studies are needed to examine the nature of the missing signals, it was confirmed that the monomeric species do not contribute to the ${ }^{13} \mathrm{C}$ SSNMR spectrum of the intermediate species in Fig. 2(b).

\section{Fluorescence assays for rehydrated lyophilized samples}

To examine the effect of lyophilization on the $A \beta(1-40)$ samples, we performed ThT fluorescence assays for $A \beta(1-40)$ samples collected at $t=0$ and $52 \mathrm{~h}$ used for Fig. $2(\mathrm{a}, \mathrm{b})$ before and after lyophilization. A fraction of the lyophilized samples used for Fig. $2(a, b)$ were rehydrated in water with the original sample volume, and the fluorescence was measured after the quick centrifugation as shown in the Table S1. The values in parentheses indicate fluorescence without centrifugation. The centrifuged data in Table S1 clearly shows that the fluorescence levels before and after lyophilization were nearly identical for both of the samples collected at $t=0$ and $52 \mathrm{~h}$. This result demonstrates that additional aggregation (or additional $\beta$ sheet formation) in lyophilzation was the minimum for the $\mathrm{A} \beta$ monomers/oligomers or $\beta$-strand intermediates.

We performed the same experiments for the intermediates with cryoprotectants such as trehalose and mannitol at $1 \mathrm{mM}$ and $300 \mathrm{mM}$. Neither trehalose nor mannitol induced substantial difference in the additional aggregation in lyophilization at $1 \mathrm{mM}$ and $300 \mathrm{mM}$. Addition of $1 \%$ polyethylene glycol to an $\mathrm{A} \beta$ solution with $1 \mathrm{mM}$ trehalose or $1 \mathrm{mM}$ mannitol resulted in fibrillization of approximately $60 \%$ of the $\mathrm{A} \beta$ intermediate after rehydration. For these reasons, we performed the ${ }^{13} \mathrm{C}$ SSNMR experiments without cryoprotectants.

We also examined whether the same amount of $A \beta$ peptides existed in the two samples used for Fig. 2 (a) and (b) by fluorescence assays. We resuspended a fraction of the samples ( $1 \mathrm{mg})$ used for SSNMR in water for an additional period of $(96 \mathrm{~h}-\mathrm{t})$ so that the samples were incubated for a total of $96 \mathrm{~h}$ for fibrillization. As shown by the values in the parentheses in the right column $(t=96 \mathrm{~h})$, both samples show comparable fluorescence without centrifugation (i. e. for fibrils) with that for the control experiment obtained by continuous incubation for $96 \mathrm{~h}$. This suggests that the peptide concentrations of the two samples were 
nearly equal even after the centrifugation and collection of the top $70 \%$ supernatant at $t=0$ or $52 \mathrm{~h}$. The results are consistent with our ${ }^{13} \mathrm{C}$ SSNMR results discussed above.

Table S1. Lyophilization dependence of ThT fluorescence

\begin{tabular}{|c|c|c|c|}
\hline & $\begin{array}{l}\text { Before lyophilization }^{\text {a }} \\
\text { With centrifugation (Without } \\
\text { centrifugation) }\end{array}$ & After lyophilization $^{\mathrm{b}}$ & $\mathrm{t}=96$ hours \\
\hline $\begin{array}{c}\text { Sample collected at } t=0 \\
\text { hour }\end{array}$ & $0.002(0.002)$ & $0.002(0.003)$ & $0.027(0.193)$ \\
\hline $\begin{array}{c}\text { Sample collected at } t=52 \\
\text { hours }\end{array}$ & $0.159(0.186)$ & $0.152(0.167)$ & $0.037(0.170)$ \\
\hline Control without freeze trap ${ }^{c)}$ & - & - & $0.042(0.196)$ \\
\hline
\end{tabular}

a. After centrifugation for $15 \mathrm{~min}$ at $13,200 \mathrm{~g}$, the supernatant in the top $70 \%$ of the $A \beta$ solution was collected and gently mixed before fluorescence measurements. The $A \beta(1-40)$ solution in the top 70 $\%$ was quickly frozen in liquid nitrogen and lyophilized for rehydration experiments. The values in the parentheses are the fluorescence measured after gentle mixing without centrifugation.

b. The lyophilized sample was resuspended in purified water of the same volume as the original solution. The fluorescence was measured after centrifugation as described above. The values in the parentheses are the fluorescence measured after gentle mixing without centrifugation after rehydration.

c. The control sample was incubated for $96 \mathrm{~h}$ without centrifugation or lyophilization.

\section{Chemical shift analysis for ${ }^{13} \mathrm{C}$ solid-state NMR of AB(1-40)}

Table S2 shows ${ }^{13} \mathrm{C}$ chemical shifts of the $\mathrm{A} \beta(1-40)$ intermediate sample collected at $t=52 \mathrm{~h}$. The sample was labeled with uniformly ${ }^{13} \mathrm{C}$ - and ${ }^{15} \mathrm{~N}$-labeled amino acids at Val18, Phe19, Ala21, Gly33, and Leu34. All the peak positions except for ${ }^{13} \mathrm{CO}$ in Phe19 and ${ }^{13} \mathrm{C}_{\delta}$ in Leu34 were based on a peak table generated by the NMRPipe program. The resonances for ${ }^{13} \mathrm{CO}$ in Phe19 were assigned from the maximum position of ${ }^{13} \mathrm{C}_{\alpha} /{ }^{13} \mathrm{CO}$ cross peaks in the $\omega_{2}$ slice taken at ${ }^{13} \mathrm{C}_{\alpha}$ resonances. For the ${ }^{13} \mathrm{C}_{\delta}$ resonance in Leu34, we assigned the approximate peak position, because the cross peaks between ${ }^{13} \mathrm{C}_{\gamma} /{ }^{13} \mathrm{C}_{\delta}$ were not well separated from other resonances. The full line widths at half height (widths) were measured from the slice along the $\omega_{2}$ dimension crossing the peak center for each peak. Dihedral angles $(\phi, \psi)$ were estimated based on isotropic chemicals shifts of ${ }^{13} \mathrm{CO},{ }^{13} \mathrm{C}_{\alpha}$, and ${ }^{13} \mathrm{C}_{\beta}$ by the TALOS software developed by Bax's group. ${ }^{16}$ Unlike other SSNMR based structural measurements, this approach efficiently produces multiple structural 
constraints from a single 2D experiment for one labeled sample. ${ }^{15}$ The values listed in Table S2 are the average of the dihedral angles from the ten protein residues having the best match between their ${ }^{13} \mathrm{C}$ solution NMR shifts and the ${ }^{13} \mathrm{C}$ SSNMR chemical shifts for the $\mathrm{A} \beta(1-40)$ intermediate sample. For Gly 33 , the TALOS software suggested two sets of dihedral angles corresponding to a right-handed helix as well as eight sets of those corresponding to a $\beta$-sheet; the average was obtained without the two outliers. The signal assignment for the 1D spectrum of the $A \beta(1-40)$ intermediate species in Fig 1(b) is shown in Fig. 1S.

Table S2. ${ }^{13} \mathrm{C}$ chemical shifts of $\mathrm{A} \beta(1-40)$ uniformly ${ }^{13} \mathrm{C}$ - and ${ }^{15} \mathrm{~N}$-labeled at Val18,Phe19, Ala21, Gly33, and Leu34 in the $\beta$-sheet intermediate and the fibril states

\begin{tabular}{|c|c|c|c|c|c|c|c|c|c|c|}
\hline Residue & $\begin{array}{l}\mathrm{CO} \\
\text { shifts } \mid \mathrm{y} \\
\text { (fibril s. }\end{array}$ & $\begin{array}{l}\text { dths } \\
\mathrm{fts})\end{array}$ & $\mathrm{C}_{\alpha}$ & & $\mathrm{C}_{\beta}$ & & $\mathrm{C}_{\gamma}$ & & $\mathrm{C}_{\delta}$ & $\begin{array}{ll}(\phi, & \psi) \\
\text { predicted } & \text { by } \\
\text { TALOS } & \end{array}$ \\
\hline Val18 & $\begin{array}{l}171.6 \\
(171.3)\end{array}$ & 3.1 & $\begin{array}{l}58.9 \\
(57.5)\end{array}$ & 3.0 & $\begin{array}{l}33.2 \\
(33.0)\end{array}$ & 3.6 & $\begin{array}{l}19.1 \\
(19.4)\end{array}$ & 2.7 & & $\begin{array}{l}(-119 \pm 7 \\
131 \pm 5)\end{array}$ \\
\hline Phe19 & $\begin{array}{l}171.6 \\
(171.9) \\
\end{array}$ & - & $\begin{array}{l}53.7 \\
(53.4) \\
\end{array}$ & 3.2 & $\begin{array}{l}41.1 \\
(42.0) \\
\end{array}$ & 3.0 & $\begin{array}{l}136.6 \\
(136.8)\end{array}$ & & $\begin{array}{l}-{ }^{\mathrm{a}} \\
-\end{array}$ & $\begin{array}{l}(-129 \pm 17 \\
155 \pm 11)\end{array}$ \\
\hline Ala21 & $\begin{array}{l}172.9 \\
(172.4)\end{array}$ & 2.9 & $\begin{array}{l}48.8 \\
(48.5)\end{array}$ & 2.6 & $\begin{array}{l}20.9 \\
(21.1)\end{array}$ & 3.5 & & & & $\begin{array}{l}(-135 \pm 18 \\
151 \pm 12)\end{array}$ \\
\hline Gly33 & $\begin{array}{l}168.9 \\
(168.9)\end{array}$ & 2.6 & $\begin{array}{l}43.0 \\
(42.7)\end{array}$ & 3.0 & & & & & & $\begin{array}{l}(-169 \pm 22 \\
169 \pm 10)\end{array}$ \\
\hline Leu34 & $\begin{array}{l}172.6 \\
(172.3) \\
\end{array}$ & 3.0 & $\begin{array}{l}52.1 \\
(51.9) \\
\end{array}$ & 2.2 & $\begin{array}{l}44.7 \\
(45.2) \\
\end{array}$ & 3.3 & $\begin{array}{l}25.3 \\
(25.0) \\
\end{array}$ & 2.8 & $\begin{array}{l}\sim 22.5^{\mathrm{a}} \\
(\sim 22.5) \\
\end{array}$ & $\begin{array}{l}(-136 \pm 12 \\
147 \pm 16)\end{array}$ \\
\hline
\end{tabular}

a. The line widths for $\mathrm{CO}$ in Phe19 and $\mathrm{C}_{\delta}$ in Leu34 were not estimated because the cross peaks for the resonance were not well separated. The peak positions for $\mathrm{C}_{\delta}$ in Leu34 are approximate values. The shifts for $\mathrm{C}_{\delta-\phi}$ in Phe19 were not well resolved.

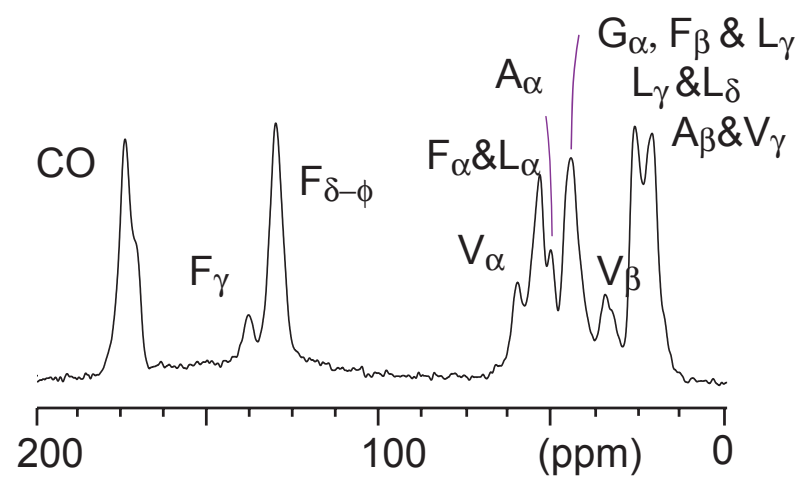

Figure 1S. Signal assignment in the 1D CPMAS spectrum in Fig. 2(b) 


\section{References:}

(1) Selkoe, D. J. Nat. Cell. Biol. 2004, 6, 1054-1061.

(2) Jarrett, J. T.; Berger, E. P.; Lansbury, P. T. Biochemistry 1993, 32, 4693-4697.

(3) Bitan, G.; Kirkitadze, M. D.; Lomakin, A.; Vollers, S. S.; Benedek, G. B.; Teplow, D. B. Proc. Natl. Acad. Sci. U. S. A. 2003, 100, 330-335.

(4) Hoshi, M.; Sato, M.; Matsumoto, S.; Noguchi, A.; Yasutake, K.; Yoshida, N.; Sato, K. Proc. Natl. Acad. Sci. U. S. A. 2003, 100, 6370-6375.

(5) Antzutkin, O. N.; Leapman, R. D.; Balbach, J. J.; Tycko, R. Biochemistry 2002, 41, 15436-15450.

(6) Antzutkin, O. N.; Balbach, J. J.; Leapman, R. D.; Rizzo, N. W.; Reed, J.; Tycko, R. Proc. Natl. Acad. Sci. U. S. A. 2000, 97, 13045-13050.

(7) Petkova, A.; Ishii, Y.; Balbach, J. J.; Antzutkin, O. A.; Leapman, R. D.; Delaglio, F.; Tycko, R. Proc. Natl. Acad. Sci. U.S.A. 2002, 99, 16742-16747.

(8) Fields, C. A.; Fields, G. B.; Noble, R. L.; Cross, T. A. Int. J. Peptide Protein Res. 1989, 33, 298-303.

(9) Walsh, D. M.; Hartley, D. M.; Kusumoto, Y.; Fezoui, Y.; Condron, M. M.; Lomakin, A.; Benedek, G. B.; Selkoe, D. J.; Teplow, D. B. J. Biol. Chem. 1999, 274, 25945-25952; Levine, H. I. Protein Sci. 1993, 2, 404-410.

(10) Levine, H. Amyloid-International Journal of Experimental and Clinical Investigation 1995, 2, 1-6; Levine, H. I. In Methods in enzymology; Wetzel, R., Ed.; Academic Press: San Diego, 1999; Vol. 309, pp 274-284; Krebs, M. R. H.; Bromley, E. H. C.; Donald, A. M. J. Struct. Biol. 2005, 149, 30 37.

(11) Tjernberg, L. O.; Callaway, D. J. E.; Tjernberg, A.; Hahne, S.; Lilliehook, C.; Terenius, L.; Thyberg, J.; Nordstedt, C. J. Biol. Chem. 1999, 274, 12619-12625; Alonso, L. G.; Garcia-Alai, M. M.; Smal, C.; Centeno, J. M.; Iacono, R.; Castano, E.; Gualfetti, P.; de Prat-Gay, G. Biochemistry 2004, 43, 3310-3317; Torrent, J.; Alvarez-Martinez, M. T.; Heitz, F.; Liautard, J. P.; Balny, C.; Lange, R. Biochemistry 2003, 42, 1318-1325.

(12) Hasegawa, K.; Yamaguchi, I.; Omata, S.; Gejyo, F.; Naiki, H. Biochemistry 1999, 38, 15514-15521.

(13) Qahwash, I.; Weiland, K. L.; Lu, Y. F.; Sarver, R. W.; Kletzien, R. F.; Yan, R. Q. J. Biol. Chem. 2003, 278, 23187-23195.

(14) Bennett, A. E.; Rienstra, C. M.; Auger, M.; Lakshmi, K. V.; Griffin, R. G. J. Chem. Phys. 1995, 103, 6951-6958.

(15) Ishii, Y. J. Chem. Phys. 2001, 114, 8473-8483.

(16) Cornilescu, G.; Delaglio, F.; Bax, A. J. Biomol. NMR 1999, 13, 289-302. 